\title{
Adverse events and management of apatinib in patients with advanced or metastatic cancers: A review
}

\author{
Minireview
}

F. $\mathrm{SHAO}^{1}, \mathrm{H} . \mathrm{ZHANG}{ }^{2}, \mathrm{X} . \mathrm{YANG}^{3}, \mathrm{X} . \mathrm{LUO}^{3}, \mathrm{~J} . \mathrm{LIU}^{3, *}$

${ }^{1}$ Department of Nuclear Medicine, Zigong First People's Hospital, Zigong, Sichuan, China; ${ }^{2}$ Department of Radiology, Dazhou Central Hospital, Dazhou, Sichuan, China; ${ }^{3}$ Department of Tropical Medicine, College of Military Preventive Medicine, Third Military Medical University, Chongqing, Chinan

*Correspondence: $\operatorname{lr} 543810125 @ 163 . c o m$

Received August 1, 2019 / Accepted November 19, 2019

\begin{abstract}
Apatinib (YN968D1) is a novel and highly selective tyrosine kinase inhibitor that inhibits vascular endothelial growth factor receptor-2 (VEGFR-2) and is approved as a third-line and subsequent-line treatment for advanced gastric adenocarcinoma or gastroesophageal junction adenocarcinoma in China. Apatinib is also widely studied in other solid tumors. With the increase in clinical research of apatinib, its adverse effects have also received widespread attention. Hence, this article summarizes the pharmacological properties of apatinib and reviews its clinical use in advanced or metastatic cancers. We highlight the common adverse reactions of apatinib in clinical applications and we also clarify the corresponding prevention and intervention measures. Overall, this review will help us better understand the safety and efficacy of apatinib treatment.
\end{abstract}

Key words: apatinib, VEGFR, adverse effects, malignant cancer, antiangiogenic targeted therapy

Angiogenesis is a critical process for tumor growth and metastasis $[1,2]$. Vascular endothelial growth factor (VEGF) is one of the most potent angiogenic factors and plays an important oncogenic role in a variety of solid tumors by binding to three vascular endothelial growth factor receptors (VEGFRs): VEGFR-1, VEGFR-2, and VEGFR-3 [3, 4]. Among these receptors, VEGFR-2, which is mainly expressed on endothelial cells, is the principal mediator of VEGFinduced angiogenic effects $[5,6]$. Therefore, the inhibition of the VEGF signaling pathway by blocking VEGFR-2 has emerged as a promising therapeutic strategy to inhibit tumor-induced angiogenesis.

Apatinib (N-[4-(1-cyano-cyclopentyl) phenyl]-2-(4-pyridylmethyl) amino-3-pyridine carboxamide), also known as YN968D1, is one of the newest oral antiangiogenic agents that selectively targets VEGFR-2 and mildly inhibits c-Kit and c-Src tyrosine kinases [7]. Apatinib was first synthesized by Advenchen Laboratories in California, USA and was developed by Jiangsu Hengrui Medicine, China [8]. Subsequently, apatinib was approved as a subsequent line treatment for patients with advanced gastric cancer in 2014 in China [9]. The use of apatinib for many cancer types, such as breast cancer, non-small cell lung cancer (NSCLC), and hepatocellular carcinoma, has also been investigated. Although apatinib has shown promising antitumor effects against diverse tumor types in several phase II/III clinical trials $[10,11]$, concerns about its safety have also been raised. Hence, in this review we highlight the common adverse events of apatinib in different tumor treatments and we also discuss the corresponding prevention measures.

\section{Molecular basis of tumor angiogenesis}

VEGFs and their receptors are critical signaling proteins produced by cells that stimulate angiogenesis. Under physiological conditions, VEGFs and VEGFRs are important to the organism because they are responsible for the generation of new blood vessels in order to provide oxygen and nutrients to peripheral tissues and to maintain normal blood perfusion [12]. However, too high concentrations of VEGFs and 
VEGFRs lead to aberrant angiogenesis and other pathological findings in the case of cancers, and the generation of new blood vessels becomes a pathological factor that dramatically worsens the patient's clinical outcomes $[13,14]$. Overexpression of VEGFs and their receptors are present in the majority of solid cancers, consequently favoring tumor growth by changing the density of microvessels in the vicinity of cells, the migration of cells and the formation of distant metastases [15-19].

VEGF is a highly conserved homodimeric glycoprotein with a molecular weight ranging between 35 and $44 \mathrm{kDa}$. VEGF has numerous isoforms, including VEGF-A, -B, -C, $-D$, $-E$, and placental growth factor (PIGF) in humans [20, 21]. Of these isoforms, VEGF-A plays a central role in tumorigenesis. Various dynamics in the cellular environment such as hypoxia, growth factors, and cytokines, can upregulate the expression of VEGF-A, thereby promoting VEGFA-mediated effects [22]. Similarly, several receptor tyrosine kinases, involving three subvariants, VEGFR-1, -2, and -3 (also known as Flt-1, KDR/Flk-1, and Flt-4 respectively), mediate the biological response to VEGF [23]. Additionally, a number of other factors, such as heparin and heparan sulfate proteoglycans, have also been reported to play a role in the cellular response to VEGF [24]. Upon activation, VEGFR undergoes autophosphorylation and subsequently activates cell type-dependent signaling cascades, such as the nitric oxide synthase (NOS) pathway, which is associated with increased endothelial cell proliferation and vascular permeability $[25,26]$, the Raf/MEK/Erk pathway, which is responsible for endothelial cell proliferation, the p38-MAPK pathway, which is linked to endothelial cell migration, and the $\mathrm{PI} 3 \mathrm{~K} / \mathrm{AKT} / \mathrm{mTOR}$ pathway, which gives rise to

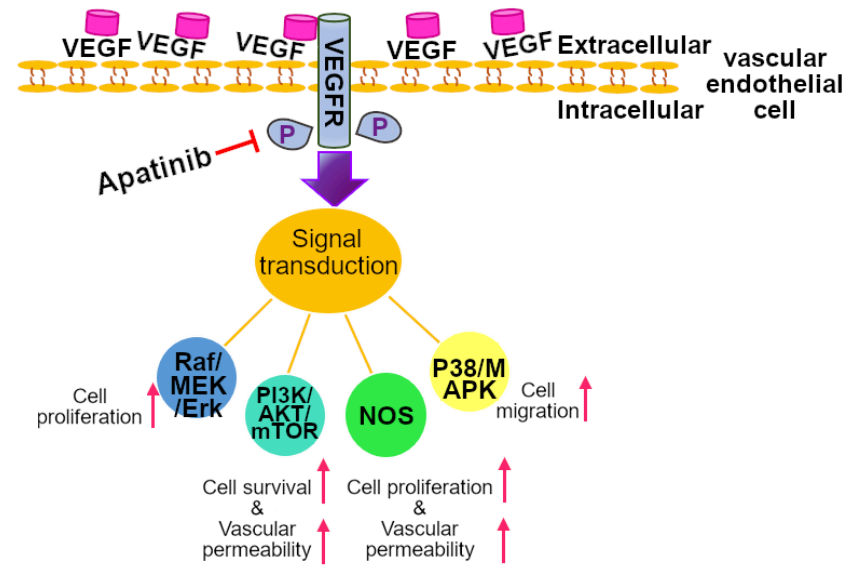

Figure 1. VEGFR and VEGF molecular pathways. Signal transduction resulting from binding between VEGFR and VEGF molecules. Upon activation, the VEGFR undergoes phosphorylation and subsequently activates cell type-dependent signaling cascades, including Raf, PI3K, NOS, and $\mathrm{P38}$, which give rise to an increase of proliferation, migration, and survival of the vascular endothelial cell, and enhance vascular permeability. Apatinib can block VEGFR phosphorylation and subsequent downstream signaling, thus inhibiting angiogenesis in many tumors. increased vascular permeability (Figure 1) [23, 27]. Among these receptors, VEGFR-2 has been found to mediate the majority of the angiogenic response to VEGF in the context of several solid tumors [13, 28]. Although the binding capacity between VEGF and VEGFR-2 is lower than that between VEGF and VEGFR-1, it results in a more significant biological activity [29], leading to the increased generation of new blood vessels, which give rise to a higher proliferation rate of vascular endothelial cells and an increased density of microvessels [30].

Given the critical roles of VEGFs and their receptors in cancer and numerous other conditions, multiple compounds capable of antagonizing the effects of VEGF or VEGFR have been developed with regard to several solid cancers [31,32]. Antiangiogenic agents in clinical use can be divided into two categories as follows: a) tyrosine kinase inhibitors (TKIs), which are chemical agents that inhibit the kinase activity of receptor tyrosine kinases (RTKs) [33] and b) protein biological agents that inhibit the VEGF/VEGFR signaling pathway, such as recombinant monoclonal antibody $(\mathrm{mAb})$ bevacizumab [34], and recombinant fusion protein ziv-aflibercept [35]. Inhibition of angiogenesis is considered a promising strategy for the treatment of cancer, and therapeutic intervention aimed at inhibiting the most critical tumor angiogenesis driver, the VEGFR-2 signaling pathway, has become a mainstay of treatment in cancer [31]. However, only a small percentage of patients using these traditional antiangiogenic agents demonstrate a survival advantage [36]. In this context, apatinib, a novel receptor tyrosine kinase inhibitor selectively targeting VEGFR-2, was developed for preclinical and clinical studies involving cancers.

\section{Preclinical and clinical data of apatinib}

Apatinib mesylate, a compound derived from valatinib, is a new inhibitor of VEGFR-2 tyrosine kinase that targets the intracellular ATP-binding site of the receptor [37] and blocks the phosphorylation and subsequent downstream signaling to interrupt angiogenesis in many tumors $[38,39]$. In addition, apatinib can also exert antitumor effects via the suppression of the RET/Src pathway leading to inhibition of cell migration and invasion in NSCLC [40]. Additionally, by promoting apoptosis and inhibiting VEGF signaling, apatinib can promote cell death in human intrahepatic cholangiocarcinoma (ICC) [41]. In addition, inhibition of autophagy increased apatinib-induced apoptosis in osteosarcoma [42], anaplastic thyroid cancer [43], and colorectal cancer [44]. Moreover, the combination of apatinib with checkpoint inhibitor immunotherapies may have synergistic effects and enhance the efficacy of both treatments in various tumors by not only antiangiogenic effects but also suppressing immune escape [45, 46]. Similarly, apatinib has also been shown to have synergistic antitumor effects in combination with endothelial growth factor receptor (EGFR) inhibitor treatment via inhibiting downstream signal conduction. 
Co-injection of apatinib and gefitinib delayed tumor growth compared with monotherapy in the NSCLC model and had a better effect on inhibiting the activation of VEGFR-2 [47].

A recent retrospective analysis revealed that the combination of an EGFR-TKI challenged with apatinib achieved an objective response rate (ORR) of $25 \%$, a disease control rate (DCR) of $100 \%$, respectively, and a median progressionfree survival (PFS) of 4.60 months (95\% confidence interval, 2.23-12.52 months) in patients, suggesting that the combination an EGFR-TKI with apatinib might be another treatment option for patients with acquired resistance to EGFR-TKIs [47]. Since apatinib combined with chemotherapy has been proven to have a strong scientific basis for additive or synergistic effects in cancer treatment, clinical trials were carried out to assess whether apatinib treatment shows survival benefit for cancer patients or whether combination therapy is more effective for cancer treatment than chemotherapy alone. A multicenter study enrolled 144 patients with metastatic gastric cancer who failed treatment with at least two chemotherapeutic regimens and were randomized to receive either a placebo or apatinib $(850 \mathrm{mg}$ once daily or $425 \mathrm{mg}$ twice daily). The median overall survival (OS) was significantly longer in patients given apatinib than in those given a placebo (4.5 vs. 2.5 months, respectively). The median PFS in patients treated with apatinib was almost twice that in those treated with a placebo (3.4 vs. 1.4 months). On average, the rate of patients receiving apatinib to achieve disease control was higher than in placebo groups ( $43 \%$ vs. $11 \%$ ) [48]. Intriguingly, similar results were supported by a phase III trial of apatinib in patients with chemotherapy-refractory advanced or metastatic adenocarcinoma of the stomach or gastroesophageal junction [49]. Additionally, another study showed that the combination of apatinib-targeted therapy with chemotherapy significantly improved the patient's complete response rate (CRR), partial response rate (PRR), overall response (OR), and DCR compared with chemotherapy alone in gastric cancer therapy [50]. Similar results were also obtained in combination with apatinib and the anti-PD-1 antibody SHR-1210 in advanced gastric or gastroesophageal junction cancer and hepatocellular carcinoma [51]. Overall, these results demonstrated that apatinib showed a survival benefit for patients with advanced or metastatic stomach or gastroesophageal junction cancers who do not respond to second-line chemotherapy. Thus, apatinib was approved for advanced or metastatic adenocarcinoma of the stomach or gastroesophageal junction cancer patients without further chemotherapy options in 2014. Beyond that, an increasing number of clinical trials have been conducted in other solid tumors. The drug has also shown promising therapeutic effects against advanced NSCLC [11], breast cancer [10], colorectal cancer [52], ovarian cancer [53], hepatocellular carcinoma [17], and thyroid cancer [54]. In summary, these results indicate that apatinib has shown an objective efficacy in multiple solid cancer patients who have experienced failure in two or more second-line chemotherapy treatments.

\section{Adverse effects and management}

Although apatinib has shown efficacy in the treatment of a wide range of cancers, its safety is also an important factor in assessing its use for clinical treatments. The most common grade III/IV adverse effects (AEs) reported in clinical trials of antiangiogenic agents were hypertension, hand-foot syndrome, and proteinuria $[55,56]$. A phase II trial of apatinib in advanced gastric cancer indicated that grade III/IV AEs were hand-foot syndrome and hypertension in more than $10 \%$ of patients, and grade III/IV AEs were thrombocytopenia, anemia, and liver toxicities in more than $5 \%$ of patients, while grade III/IV hematologic toxicities and fatigue were rarely noted [48]. The results of another phase III trial of apatinib on chemotherapy-refractory advanced cancer of the stomach or gastroesophageal junction reported grade III/IV AEs including hand-foot syndrome (8.5\% vs. $0 \%$, respectively), hypertension ( $4.5 \%$ vs. $0 \%$, respectively), and proteinuria $(2.3 \%$ vs. $0 \%$, respectively). Moreover, common hematologic toxicities related to apatinib vs. placebo included anemia ( $6.3 \%$ vs. $4.4 \%$, respectively) and neutropenia (5.7\% vs. $1.1 \%$, respectively). A low incidence of grade III/IV gastrointestinal symptoms including decreased appetite and diarrhea occurred in 3.9\% of patients with apatinib treatment. Additionally, fatigue was a common AE among patients enrolled in this study. In total, $20.5 \%$ and $14.3 \%$ of patients receiving apatinib or placebo, respectively, experienced fatigue. However, only approximately $2 \%$ of patients experienced grade III/IV fatigue [49]. Furthermore, the emerging toxicity profile was further supported by the results obtained in many other solid cancers, such as non-triple-negative metastatic breast cancer [10], and thyroid cancer [54]. Previous studies have identified several major toxicities associated with the use of apatinib, so how can clinicians prevent or treat these complications (Table 1)?

Hypertension. Although there are no published prospectively collected data on the time course of BP alterations in patients receiving apatinib who experience hypertension, various strategies for disrupting the VEGF signaling pathway (VSP) demonstrate similar effects on the normal vasculature over the same time course in animal models $[57,58]$. Therefore, despite differences in the pharmacokinetics of apatinib and other antiangiogenic agents, in the absence of data, similar surveillance methods are appropriate and suggested.

According to the guidelines that have been published by the Cardiovascular Toxicities Panel and Angiogenesis Task Force of the National Cancer Institute Investigational Drug Steering Committee for clinicians to monitor and treat antiangiogenic-associated hypertension [59], once treatment is initiated, active monitoring of blood pressure (BP) should be performed regularly and continued after treatment discontinuation. Patients with non-high risk factors treated with a VSP inhibitor have a target BP of no more than 140/90 $\mathrm{mmHg}$, which is consistent with the JNC guidelines [60]. For some patients in the higher added risk cohort, the goal 
Table 1. Adverse events and management approaches of apatinib.

\begin{tabular}{|c|c|}
\hline Event & Management \\
\hline \multirow[t]{3}{*}{ Hypertension } & Dynamic monitoring of blood pressure regularly \\
\hline & Standard antihypertensive agents \\
\hline & Other parameters such as medical comorbidities, cardiovascular risk factors, and drug interactions should be considered \\
\hline \multirow[t]{2}{*}{ Proteinuria } & Routine urinalysis for screening proteinuria \\
\hline & $\begin{array}{l}\text { Proteinuria of grade } \geq \text { II, suspend the medication until proteinuria falls below the threshold; the proteinuria of grade } \geq \text { II occurs } \\
\text { again after apatinib recovery, the dose can be lowered and continue to be used }\end{array}$ \\
\hline \multirow[t]{3}{*}{ Hand-foot syndrome } & Routine assessments \\
\hline & $\begin{array}{l}\text { Education on self-care (e.g., strengthen skin care, keep skin clean, avoid secondary infections; avoid stress or frictions; use mois- } \\
\text { turizers or lubricants containing urea and corticosteroids), Topical antifungal or antibiotic treatment if necessary }\end{array}$ \\
\hline & $\begin{array}{l}3 \text { consecutive } \geq \text { II grades of hand-foot syndrome, and there is a tendency to aggravate, suspend the medication; } \geq \text { II grades of } \\
\text { hand-foot syndrome reappears after apatinib is resumed, reduced dose; the adverse reactions continue, stop the drug }\end{array}$ \\
\hline \multirow[t]{3}{*}{ Bleeding } & Monitor bleeding closely \\
\hline & $\begin{array}{l}\text { Patients with anticoagulant therapy combined with warfarin should be routinely monitored for prothrombin time (APTT) and } \\
\text { internationalized normalized ratio (INR), and pay attention to clinical signs of bleeding }\end{array}$ \\
\hline & $\begin{array}{l}\text { For patients with severe (III/IV grade) bleeding, stop the drug temporarily; the severe hemorrhage occurs again after apatinib is } \\
\text { recovery, the drug can be continued after the dose is reduced; the adverse reaction persists, stop the drug }\end{array}$ \\
\hline \multirow[t]{3}{*}{ Cardiotoxicity } & Monitor ECG and cardiac function closely \\
\hline & $\begin{array}{l}\text { A grade III/IV adverse reaction occurs, suspend the drug; the grade III/IV adverse reaction occurs again after apatinib is re- } \\
\text { sumed, the drug can be continued after one dose is lowered; the adverse reaction continues, stop the drug }\end{array}$ \\
\hline & $\begin{array}{l}\text { Patients with III/IV grade cardiac insufficiency or echocardiography showed a left ventricular ejection fraction }<50 \% \text { : discon- } \\
\text { tinue the medication }\end{array}$ \\
\hline \multirow[t]{4}{*}{ Hepatotoxicity } & Check liver function regularly every 2 weeks during the first two months of taking apatinib \\
\hline & Patients with elevated serum transaminase and total bilirubin should use this agent with caution \\
\hline & Patients with previous liver dysfunction should be cautious and closely monitored liver function when taking apatinib \\
\hline & Patients with severe hepatic insufficiency: prohibit the use of apatinib \\
\hline \multirow[t]{4}{*}{ Nausea and vomiting } & Non-pharmacological interventions (e.g., ginger, acupuncture, acupressure, music therapy) \\
\hline & $\begin{array}{l}\text { Dietary interventions (small, multiple meals, avoiding food aromas and other odors, avoiding spicy, fatty, or salty food, and } \\
\text { taking antiemetics before meal) }\end{array}$ \\
\hline & Psychological support \\
\hline & Breakthrough vomiting: combined medication to stop vomiting \\
\hline Diarrhea & $\begin{array}{l}\text { The III/IV grade diarrhea occurs, suspend the medication; the grade III/IV diarrhea occurs again after the medication is re- } \\
\text { sumed, the dose is lowered; the adverse effect continues, stop the drug }\end{array}$ \\
\hline \multirow[t]{3}{*}{ Fatigue } & Education for the patients and their families \\
\hline & Non-pharmacologic interventions (e.g., exercise and psychosocial counseling) \\
\hline & Medications for the treatment of pain, emotional distress, sleep disturbance, and anemia \\
\hline
\end{tabular}

BP should be adjusted to a lower value. For younger patients who are normotensive and at a low baseline risk, antihypertensive treatment should be initiated in any patient having an increase in diastolic BP of $20 \mathrm{mmHg}$ or greater even if the absolute measurement is not above $140 / 90 \mathrm{mmHg}$. No consensus or specific guidelines exist for choosing antihypertensive agents for patients experiencing antiangiogenicassociated hypertension. Meanwhile, a variety of conventional drugs, including thiazide diuretics, beta-blockers, dihydropyridines and non-dihydropyridine calcium channel antagonists, angiotensin-converting enzymes inhibitors, and angiotensin receptor antagonists, have been used to treat VSP inhibitor-induced hypertension. Each type of these antihypertensive drugs works well on an individual patient basis. However, other parameters, such as medical comorbidities, cardiovascular risk factors, and drug interactions should be considered to determine whether to start using specific antihypertensive drugs [59].

Proteinuria. Patients receiving antiangiogenic drugs should be monitored by routine urinalysis to screen for proteinuria $[61,62]$. During the first two months of taking the medication, routine urinalysis should be checked every 2 weeks and then every 4 weeks. If proteinuria occurs, the patient should seek medical attention immediately. If proteinuria of grade $\geq \mathrm{II}$ occurs, it is recommended to suspend the medication; if the proteinuria of grade $\geq \mathrm{II}$ occurs again after recovery, the dose can be lowered and continue to be used.

Hand-foot syndrome. Hand-foot syndrome occurs more than 3 weeks after taking the drug, and current guidelines for the treatment of hand-foot syndrome include routine assessments and patient education on self-care, including strengthening skin care, keeping the skin clean, avoiding secondary 
infections, avoiding stress or friction, using moisturizers or lubricants containing urea and corticosteroids, and if necessary, using topical antifungal or antibiotic treatment $[62,63]$. If there are 3 consecutive occurrences of hand-foot syndrome at a grade $\geq \mathrm{II}$, and there is a tendency of aggravation, it is recommended to suspend the medication; if hand-foot syndrome at a grade $\geq \mathrm{II}$ reappears after the medication is resumed, the dose can be lowered. If the adverse reactions continue, it is recommended to stop the drug.

Bleeding. VEGFR inhibitor antitumor drugs have the potential to increase the risk of bleeding. In phase III clinical studies, the observed bleeding symptoms included gastrointestinal bleeding, hematemesis, hemoptysis, fecal occult blood, urinary occult blood, skin bleeding, and hemorrhagic rupture of liver metastases and a common serious adverse reaction was upper gastrointestinal bleeding $[64,65]$. The bleeding should be closely monitored when using the drug. Patients with anticoagulant therapy combined with warfarin should be routinely monitored for prothrombin time (APTT) and internationalized normalized ratio (INR), and attention should be paid to clinical signs of bleeding. Additionally, for patients with severe (III/ IV grade) bleeding, it is recommended to temporarily stop the drug; if the severe hemorrhage occurs again after the medication is resumed, the drug can be continued after the dose is lowered. If the adverse reaction persists, it is recommended to stop the drug.

Cardiotoxicity. It has been observed in clinical studies that taking apatinib may cause an abnormal electrocardiogram (ECG), including prolonged QT interval or sinus bradycardia [66]. Apatinib should be used with caution in patients with a known history of a prolonged QT interval, in patients taking antiarrhythmic drugs, or in patients with potential heart disease, bradycardia, or electrolyte imbalance. In addition, care should be taken to closely monitor the ECG and cardiac functions while taking the medication. If a grade III/IV adverse reaction occurs, it is recommended to suspend the medication; if the grade III/IV adverse reaction occurs again after the medication is resumed, the drug can be continued after the dose is lowered. However, if the adverse reaction continues, it is recommended to stop the drug. Furthermore, in patients with grade III/IV cardiac insufficiency or with echocardiography that showed a left ventricular ejection fraction $<50 \%$, it is recommended to discontinue using the drug.

Hepatotoxicity. Taking apatinib can cause a transient transaminase elevation or an increase in total bilirubin $[67,68]$. Therefore, patients with elevated serum transaminase and total bilirubin should use this agent with caution. Moreover, patients with previous liver dysfunction should be cautious and closely monitored when taking apatinib. It is recommended to check liver function every 2 weeks during the first two months of taking the medication. In addition, this drug is contraindicated in patients with severe hepatic insufficiency.
Others. Taking apatinib may cause nausea and vomiting. Generally, non-pharmacological interventions that may prevent or help control nausea include ginger, acupuncture, acupressure, music therapy, and psychological support [69]. Additionally, dietary interventions, such as eating small, multiple meals, avoiding food aromas and other odors, avoiding spicy, fatty, or salty food, and taking antiemetics before a meal, may also be useful [70]. In addition, for breakthrough vomiting, a combination of different classes of antiemetics should be used to stop the patient from vomiting [69].

In patients with diarrhea, taking apatinib may affect the absorption of this agent; therefore, the disease leading to diarrhea should be actively treated, and this product can be taken after improvement. If a III/IV grade diarrhea occurs while using this product, suspend the medication; if the grade III/IV diarrhea occurs again after the medication is resumed, the dose may be lowered. If the adverse effect continues, it is recommended to stop the drug.

Every patient receiving chemotherapy should undergo fatigue screening $[71,72]$, and fatigue is a common side effect of taking apatinib. Interventions for fatigue include educating the patients and their families; using non-pharmacologic interventions, such as exercise and psychosocial counseling, and taking medications for the treatment of pain, emotional distress, sleep disturbance, and anemia [72].

\section{Conclusion}

Angiogenesis plays a major role in the development and progression of numerous solid cancers, and targeting angiogenesis has been proven to be effective in many types of cancer including lung, breast, and colon cancers [73, 74]. In a number of ongoing clinical studies, apatinib is widely used as a novel antiangiogenic drug for the treatment of various advanced or metastatic tumors. Notably, the addition of apatinib significantly improved the response rate, PFS and OS durations of patients with previously treated and untreated advanced chemotherapy-refractory solid cancers $[75,76]$. In view of the positive results of apatinib in patients with advanced or metastatic cancers, various other clinical trials were performed to assess the efficacy and tolerability of apatinib with or without the combination of chemotherapy in various cancers. This suggests that apatinib appears to be effective against many advanced solid cancers after the failure of chemotherapy or other targeted therapies $[49,52]$. In addition, because the goal of targeted drug therapy is to maintain target inhibition continuously over the course of the treatment, the most convenient regimen is oral administration once a day with an ideal plasma half-life of 8-12 hours [13]. Considering that the half-life of apatinib is 9 hours and given once per day, it represents a promising drug that maintains an adequate steady-state and accurately downregulates its targets, VEGFR-2. 
Targeted therapy is also associated with a wide spectrum of adverse events that can significantly alter the quality of life of the treated patients, especially if several adverse events coexist in a given patient. As research progresses, the safety and tolerability of apatinib have also received widespread attention. Awareness among prescribing clinicians and adequate patient education are critical for the safe use of these agents. Moreover, individualized risk assessments, regular observations, and avoidance of drugs that add to the toxicity of apatinib treatment can prevent these harmful adverse effects. In a word, high awareness of the possibility of adverse events in patients treated with apatinib may improve the quality of life, help identify new syndromes, and prevent treatment-related mortality in these patients.

In summary, apatinib is effective against most advanced solid tumors that are refractory to chemotherapy, confirming the potential application of apatinib in many advanced solid tumors. In addition, the safety of apatinib has also received extensive attention. Reasonable prevention and treatment of possible side effects are beneficial to reverse adverse reactions and improve quality of life.

Acknowledgments: This work was supported by the National Natural Science Foundation of China (NO.81773396).

\section{References}

[1] RAMJIAWAN RR, GRIFFIOEN AW, DUDA DG. Antiangiogenesis for cancer revisited: Is there a role for combinations with immunotherapy? Angiogenesis 2017; 20: 185204. https://doi.org/10.1007/s10456-017-9552-y

[2] VIALLARD C, LARRIVEE B. Tumor angiogenesis and vascular normalization: alternative therapeutic targets. Angiogenesis 2017; 20: 409-426. https://doi.org/10.1007/s10456017-9562-9

[3] COSTACHE MI, IOANA M, IORDACHE S, ENE D, COSTACHE CA et al. VEGF Expression in Pancreatic Cancer and Other Malignancies: A Review of the Literature. Rom J Intern Med 2015; 53: 199-208. https://doi.org/10.1515/ rjim-2015-0027

[4] BHATTACHARYA R, FAN F, WANG R, YE X, XIA L et al. Intracrine VEGF signalling mediates colorectal cancer cell migration and invasion. Br J Cancer 2017; 117: 848-855. https://doi.org/10.1038/bjc.2017.238

[5] KIM KL, SUH W. Apatinib, an Inhibitor of Vascular Endothelial Growth Factor Receptor 2, Suppresses Pathologic Ocular Neovascularization in Mice. Invest Ophthalmol Vis Sci 2017; 58: 3592-3599. https://doi.org/10.1167/iovs.17-21416

[6] GLADE-BENDER J, KANDEL JJ, YAMASHIRO DJ. VEGF blocking therapy in the treatment of cancer. Expert Opin Biol Ther 2003; 3: 263-276. https://doi. org/10.1517/14712598.3.2.263

[7] TIAN S, QUAN H, XIE C, GUO H, LU F et al. YN968D1 is a novel and selective inhibitor of vascular endothelial growth factor receptor-2 tyrosine kinase with potent activity in vitro and in vivo. Cancer Sci 2011; 102: 1374-1380. https://doi. org/10.1111/j.1349-7006.2011.01939.x
[8] DING J, CHEN X, DAI X, ZHONG D. Simultaneous determination of apatinib and its four major metabolites in human plasma using liquid chromatography-tandem mass spectrometry and its application to a pharmacokinetic study. J Chromatogr B Analyt Technol Biomed Life Sci 2012; 895-896: 108-115. https://doi.org/10.1016/j. jchromb.2012.03.027

[9] ZHANG H. Apatinib for molecular targeted therapy in tumor. Drug Des Devel Ther 2015; 9: 6075-6081. https://doi. org/10.2147/DDDT.S97235

[10] HU X, CAO J, HU W, WU C, PAN Y et al. Multicenter phase II study of apatinib in non-triple-negative metastatic breast cancer. BMC Cancer 2014; 14: 820. https://doi. org/10.1186/1471-2407-14-820

[11] LANGER CJ, MOK T, POSTMUS PE. Targeted agents in the third-/fourth-line treatment of patients with advanced (stage III/IV) non-small cell lung cancer (NSCLC). Cancer Treat Rev 2013; 39: 252-260. https://doi.org/10.1016/j. ctrv.2012.05.003

[12] LAAKKONEN JP, LAHTEENVUO J, JAUHIAINEN S, HEIKURA T, YLA-HERTTUALA S. Beyond endothelial cells: Vascular endothelial growth factors in heart, vascular anomalies and placenta. Vascul Pharmacol 2019; 112: 91101. https://doi.org/10.1016/j.vph.2018.10.005

[13] ROVIELLO G, RAVELLI A, POLOM K, PETRIOLI R, MARANO L et al. Apatinib: A novel receptor tyrosine kinase inhibitor for the treatment of gastric cancer. Cancer Lett 2016; 372: 187-191. https://doi.org/10.1016/j.canlet.2016.01.014

[14] KYZAS PA, CUNHA IW, IOANNIDIS JP. Prognostic significance of vascular endothelial growth factor immunohistochemical expression in head and neck squamous cell carcinoma: a meta-analysis. Clin Cancer Res 2005; 11: 14341440. https://doi.org/10.1158/1078-0432.CCR-04-1870

[15] YU XM, LO CY, CHAN WF, LAM KY, LEUNG P et al. Increased expression of vascular endothelial growth factor $\mathrm{C}$ in papillary thyroid carcinoma correlates with cervical lymph node metastases. Clin Cancer Res 2005; 11: 8063-8069. https://doi.org/10.1158/1078-0432.CCR-05-0646

[16] MAROOF H, ISLAM F, DONG L, AJJIKUTTIRA P, GOPALAN V et al. Liposomal Delivery of miR-34b-5p Induced Cancer Cell Death in Thyroid Carcinoma. Cells 2018; 7: E265. https://doi.org/10.3390/cells7120265

[17] HAN Z, HE Z, WANG C, WANG Q. The effect of apatinib in the treatment of sorafenib resistant metastatic hepatocellular carcinoma: A case report. Medicine (Baltimore) 2018; 97: e13388. https://doi.org/10.1097/MD.0000000000013388

[18] SHARMA K, PATIDAR K, ALI MA, PATIL P, HOOD EA et al. Structure base Virtual screening for the identification of high affinity compounds as potent VEGFR2 inhibitors for the treatment of Renal Cell Carcinoma. Curr Top Med Chem 2018; 18: 2174-2185. https://doi.org/10.2174/156802661966 6181130142237

[19] BRADSHAW M, MANSFIELD A, PEIKERT T. The role of vascular endothelial growth factor in the pathogenesis, diagnosis and treatment of malignant pleural effusion. Curr Oncol Rep 2013; 15: 207-216. https://doi.org/10.1007/s11912013-0315-7 
[20] ZACHARY I. Signaling mechanisms mediating vascular protective actions of vascular endothelial growth factor. Am J Physiol Cell Physiol 2001; 280: C1375-1386. https://doi. org/10.1152/ajpcell.2001.280.6.C1375

[21] HICKLIN DJ, ELLIS LM. Role of the vascular endothelial growth factor pathway in tumor growth and angiogenesis. J Clin Oncol 2005; 23: 1011-1127. https://doi.org/10.1200/ JCO.2005.06.081

[22] HOEBEN A, LANDUYT B, HIGHLEY MS, WILDIERS H, VAN OOSTEROM AT et al. Vascular endothelial growth factor and angiogenesis. Pharmacol Rev 2004; 56: 549-580. https://doi.org/10.1124/pr.56.4.3

[23] FERRARA N, GERBER HP, LECOUTER J. The biology of VEGF and its receptors. Nat Med 2003; 9: 669-676. https:// doi.org/10.1038/nm0603-669

[24] ROBINSON CJ, STRINGER SE. The splice variants of vascular endothelial growth factor (VEGF) and their receptors. J Cell Sci 2001; 114: 853-865.

[25] NEVES KB, RIOS FJ, VAN DER MEY L, ALVES-LOPES $\mathrm{R}$, CAMERON AC et al. VEGFR (Vascular Endothelial Growth Factor Receptor) Inhibition Induces Cardiovascular Damage via Redox-Sensitive Processes. Hypertension 2018; 71: 638-647. https://doi.org/10.1161/HYPERTENSIONAHA.117.10490

[26] CHEN Y, MATHY NW, LU H. The role of VEGF in the diagnosis and treatment of malignant pleural effusion in patients with nonsmall cell lung cancer (Review). Mol Med Rep 2018; 17: 8019-8030. https://doi.org/10.3892/mmr.2018.8922

[27] LEE SH, JEONG D, HAN YS, BAEK MJ. Pivotal role of vascular endothelial growth factor pathway in tumor angiogenesis. Ann Surg Treat Res 2015; 89: 1-8. https://doi. org/10.4174/astr.2015.89.1.1

[28] DVORAK HF. Vascular permeability factor/vascular endothelial growth factor: a critical cytokine in tumor angiogenesis and a potential target for diagnosis and therapy. J Clin Oncol 2002; 20: 4368-4380. https://doi.org/10.1200/ JCO.2002.10.088

[29] EBOS JM, BOCCI G, MAN S, THORPE PE, HICKLIN DJ et al. A naturally occurring soluble form of vascular endothelial growth factor receptor 2 detected in mouse and human plasma. Mol Cancer Res 2004; 2: 315-326.

[30] LONGO R, GASPARINI G. Challenges for patient selection with VEGF inhibitors. Cancer Chemother Pharmacol 2007; 60: 151-170. https://doi.org/10.1007/s00280-006-0403-6

[31] FALCON BL, CHINTHARLAPALLI S, UHLIK MT, PYTOWSKI B. Antagonist antibodies to vascular endothelial growth factor receptor 2 (VEGFR-2) as anti-angiogenic agents. Pharmacol Ther 2016; 164: 204-225. https://doi. org/10.1016/j.pharmthera.2016.06.001

[32] VILLARUZ LC, SOCINSKI MA. The role of anti-angiogenesis in non-small-cell lung cancer: an update. Curr Oncol Rep 2015; 17: 26. https://doi.org/10.1007/s11912-015-0448-y

[33] FERRARA N, KERBEL RS. Angiogenesis as a therapeutic target. Nature 2005; 438: 967-974. https://doi.org/10.1038/ nature 04483

[34] WANG Y, FEI D, VANDERLAAN M, SONG A. Biological activity of bevacizumab, a humanized anti-VEGF antibody in vitro. Angiogenesis 2004; 7: 335-345. https://doi. org/10.1007/s10456-004-8272-2
[35] MITCHELL EP. Targeted therapy for metastatic colorectal cancer: role of aflibercept. Clin Colorectal Cancer 2013; 12: 73-85. https://doi.org/10.1016/j.clcc.2012.08.001

[36] ROVIELLO G, PETRIOLI R, MARANO L, POLOM K, MARRELLI $\mathrm{D}$ et al. Angiogenesis inhibitors in gastric and gastroesophageal junction cancer, Gastric cancer. Gastric Cancer 2016; 19: 31-41. https://doi.org/10.1007/s10120015-0537-5

[37] HOLMES K, ROBERTS OL, THOMAS AM, CROSS MJ. Vascular endothelial growth factor receptor-2: structure, function, intracellular signalling and therapeutic inhibition. Cell Signal 2007; 19: 2003-2012. https://doi.org/10.1016/j. cellsig.2007.05.013

[38] YANG C, QIN S. Apatinib targets both tumor and endothelial cells in hepatocellular carcinoma. Cancer Med 2018; 7: 4570-4583. https://doi.org/10.1002/cam4.1664

[39] WU S, ZHOU JJ, GUO J, HUA Z, LI JC et al. Apatinib inhibits tumor growth and angiogenesis in PNET models. Endocr Connect 2019; 8: 8-19. https://doi.org/10.1530/EC-180397

[40] LIN C, WANG S, XIE W, ZHENG R, GAN Y et al. Apatinib inhibits cellular invasion and migration by fusion kinase KIF5B-RET via suppressing RET/Src signaling pathway. Oncotarget 2016; 7: 59236-59244. https://doi.org/10.18632/ oncotarget.10985

[41] Peng H, Zhang Q, Li J, Zhang N, Hua Y et al. Apatinib inhibits VEGF signaling and promotes apoptosis in intrahepatic cholangiocarcinoma. Oncotarget 2016; 7: 17220-17229. https://doi.org/10.18632/oncotarget.7948

[42] LIU K, REN T, HUANG Y, SUN K, BAO X et al. Apatinib promotes autophagy and apoptosis through VEGFR2/ STAT3/BCL-2 signaling in osteosarcoma. Cell Death Dis 2017; 8: e3015. https://doi.org/10.1038/cddis.2017.422

[43] FENG H, CHENG X, KUANG J, CHEN L, YUEN S et al. Apatinib-induced protective autophagy and apoptosis through the AKT-mTOR pathway in anaplastic thyroid cancer. Cell Death Dis 2018; 9: 1030. https://doi.org/10.1038/ s41419-018-1054-3

[44] CHENG X, FENG H, WU H, JIN Z, SHEN X et al. Targeting autophagy enhances apatinib-induced apoptosis via endoplasmic reticulum stress for human colorectal cancer. Cancer Lett 2018; 431: 105-114. https://doi.org/10.1016/j. canlet.2018.05.046

[45] ZHENG B, REN T, HUANG Y, GUO W. Apatinib inhibits migration and invasion as well as PD-L1 expression in osteosarcoma by targeting STAT3. Biochem Biophys Res Commun 2018; 495: 1695-1701. https://doi.org/10.1016/j. bbrc.2017.12.032

[46] MANEGOLD C, DINGEMANS AC, GRAY JE, NAKAGAWA K, NICOLSON $\mathrm{M}$ et al. The Potential of Combined Immunotherapy and Antiangiogenesis for the Synergistic Treatment of Advanced NSCLC. J Thorac Oncol 2017; 12: 194-207. https://doi.org/10.1016/j.jtho.2016.10.003

[47] LI F, ZHU T, CAO B, WANG J, LIANG L. Apatinib enhances antitumour activity of EGFR-TKIs in non-small cell lung cancer with EGFR-TKI resistance. Eur J Cancer 2017; 84: 184-192. https://doi.org/10.1016/j.ejca.2017.07.037 
[48] LI J, QIN S, XU J, GUO W, XIONG J et al. Apatinib for chemotherapy-refractory advanced metastatic gastric cancer: results from a randomized, placebo-controlled, parallel-arm, phase II trial. J Clin Oncol 2013; 31: 3219-3225. https://doi. org/10.1200/JCO.2013.48.8585

[49] LI J, QIN S, XU J, XIONG J, WU C et al. Randomized, Double-Blind, Placebo-Controlled Phase III Trial of Apatinib in Patients With Chemotherapy-Refractory Advanced or Metastatic Adenocarcinoma of the Stomach or Gastroesophageal Junction. J Clin Oncol 2016; 34: 1448-1454. https://doi. org/10.1200/JCO.2015.63.5995

[50] CHENG H, SUN A, GUO Q, ZHANG Y. Efficacy and safety of apatinib combined with chemotherapy for the treatment of advanced gastric cancer in the Chinese population: a systematic review and meta-analysis. Drug Des Devel Ther 2018; 12: 2173-2183. https://doi.org/10.2147/DDDT.S170678

[51] XU JM, ZHANG Y, JIA R, YUE CY, CHANG L et al. AntiPD-1 Antibody SHR-1210 combined with Apatinib for Advanced Hepatocellular Carcinoma, Gastric or Esophagogastric Junction Cancer: An Open-label, Dose Escalation and Expansion Study. Clin Cancer Res 2019; 25: 515-523. https:// doi.org/10.1158/1078-0432.CCR-18-2484

[52] LIAO X, LI H, LIU Z, LIAO S, LI Q et al. Clinical efficacy and safety of apatinib in patients with advanced colorectal cancer as the late-line treatment. Medicine (Baltimore) 2018; 97: e13635. https://doi.org/10.1097/MD.0000000000013635

[53] LAN CY, WANG Y, XIONG Y, LI JD, SHEN JX et al. Apatinib combined with oral etoposide in patients with platinum-resistant or platinum-refractory ovarian cancer (AEROC): a phase 2, single-arm, prospective study. Lancet Oncol 2018; 19: 1239-1246. https://doi.org/10.1016/S14702045(18)30349-8

[54] ZHANG X, WANG C, LIN Y. Pilot Dose Comparison of Apatinib in Chinese Patients With Progressive RadioiodineRefractory Differentiated Thyroid Cancer. J Clin Endocrinol Metab 2018; 103: 3640-3646. https://doi.org/10.1210/ jc.2018-00381

[55] FUCHS CS, TOMASEK J, YONG CJ, DUMITRU F, PASSALACQUA R et al. Ramucirumab monotherapy for previously treated advanced gastric or gastro-oesophageal junction adenocarcinoma (REGARD): an international, randomised, multicentre, placebo-controlled, phase 3 trial. Lancet 2014; 383: 31-39. https://doi.org/10.1016/S0140-6736(13)61719-5

[56] LOS M, ROODHART JM, VOEST EE. Target practice: lessons from phase III trials with bevacizumab and vatalanib in the treatment of advanced colorectal cancer. Oncologist 2007; 12: 443-450. https://doi.org/10.1634/theoncologist.12-4-443

[57] BAFFERT F, LE T, SENNINO B, THURSTON G, KUO CJ et al. Cellular changes in normal blood capillaries undergoing regression after inhibition of VEGF signaling. Am J Physiol Heart Circ Physiol 2006; 290: H547-559. https://doi. org/10.1152/ajpheart.00616.2005

[58] KAMBA T, TAM BY, HASHIZUME H, HASKELL A, SENNINO B et al. VEGF-dependent plasticity of fenestrated capillaries in the normal adult microvasculature. Am J Physiol Heart Circ Physiol 2006; 290: H560-576. https://doi. org/10.1152/ajpheart.00133.2005
[59] MAITLAND ML, BAKRIS GL, BLACK HR, CHEN HX, DURAND JB et al. Initial assessment, surveillance, and management of blood pressure in patients receiving vascular endothelial growth factor signaling pathway inhibitors. J Natl Cancer Inst 2010; 102: 596-604. https://doi.org/10.1093/ jnci/djq091

[60] JAMES PA, OPARIL S, CARTER BL, CUSHMAN WC, DENNISON-HIMMELFARB C et al. 2014 evidence-based guideline for the management of high blood pressure in adults: report from the panel members appointed to the Eighth Joint National Committee (JNC 8). JAMA 2014; 311: 507-520. https://doi.org/10.1001/jama.2013.284427

[61] JIN K, SHEN Y, HE K, XU Z, LI G et al. Aflibercept (VEGF Trap): one more double-edged sword of anti-VEGF therapy for cancer? Clin Transl Oncol 2010; 12: 526-532. https://doi. org/10.1007/s12094-010-0550-4

[62] GRENON NN. Managing toxicities associated with antiangiogenic biologic agents in combination with chemotherapy for metastatic colorectal cancer. Clin J Oncol Nurs 2013; 17: 425-433. https://doi.org/10.1188/13.CJON.425-433

[63] SCHMIDINGER M, DANESI R. Management of Adverse Events Associated with Cabozantinib Therapy in Renal Cell Carcinoma. Oncologist 2018; 23: 306-315. https://doi. org/10.1634/theoncologist.2017-0335

[64] ZHU X, LIU M, LV J, GUO L, LI C et al. Good local tumor control but lethal hemorrhage after apatinib treatment for intractable squamous carcinoma of the floor of the mouth: a case report. Onco Targets Ther 2018; 11: 8909-8913. https:// doi.org/10.2147/OTT.S180358

[65] WANG W, ZHANG L, XIE Y, ZHEN T, SU G et al. Fatal hemoptysis in patients with advanced esophageal cancer treated with apatinib. Onco Targets Ther 2018; 11: 2565-2570. https://doi.org/10.2147/OTT.S150555

[66] LIU Y, ZHOU C, ZHANG K, FENG Y, ZHANG R. The combination of apatinib and S-1 for the treatment of advanced gastric cancer in China: A meta-analysis of randomized controlled trials. Medicine (Baltimore) 2018; 97: e13259. https:// doi.org/10.1097/MD.0000000000013259

[67] ZHEN L, JIALI C, YONG F, HAN X, HONGMING P et al. The Efficacy and Safety of Apatinib Treatment for Patients with Unresectable or Relapsed Liver Cancer: a retrospective study. J Cancer 2018; 9: 2773-2777. https://doi.org/10.7150/ jca. 26376

[68] YU WC, ZHANG KZ, CHEN SG, LIU WF. Efficacy and Safety of apatinib in patients with intermediate/advanced hepatocellular carcinoma: A prospective observation study. Medicine (Baltimore) 2018; 97: e9704. https://doi. org/10.1097/MD.0000000000009704

[69] BERGER MJ, ETTINGER DS, ASTON J, BARBOUR S, BERGSBAKEN J et al. NCCN Guidelines Insights: Antiemesis, Version 2.2017. J Natl Compr Canc Netw 2017; 15: 883-893. https://doi.org/10.6004/jnccn.2017.0117

[70] TIPTON JM, MCDANIEL RW, BARBOUR L, JOHNSTON MP, KAYNE M et al. Putting evidence into practice: evidence-based interventions to prevent, manage, and treat chemotherapy-induced nausea and vomiting. Clin J Oncol Nurs 2007; 11: 69-78. https://doi.org/10.1188/07.CJON.6978 
[71] BERGER AM, ABERNETHY AP, ATKINSON A, BARSEVICK AM, BREITBART WS et al. NCCN Clinical Practice Guidelines Cancer-related fatigue. J Natl Compr Canc Netw 2010; 8: 904-931. https://doi.org/10.6004/jnccn.2010.0067

[72] BERGER AM, MOONEY K, ALVAREZ-PEREZ A, BREITBART WS, CARPENTER KM et al. Cancer-Related Fatigue, Version 2.2015. J Natl Compr Canc Netw 2015; 13: 10121039. https://doi.org/10.6004/jnccn.2015.0122

[73] FOLKMAN J. Angiogenesis in cancer, vascular, rheumatoid and other disease. Nat Med 1995; 1: 27-31. https://doi. org/10.1038/nm0195-27
[74] TANIGAWA N, AMAYA H, MATSUMURA M, SHIMOMATSUYA T. Correlation between expression of vascular endothelial growth factor and tumor vascularity, and patient outcome in human gastric carcinoma. J Clin Oncol 1997; 15: 826-832. https://doi.org/10.1200/JCO.1997.15.2.826

[75] YAN X, WANG Q, WANG H, LI P, ZHANG G et al. Apatinib as maintenance therapy in extensive-stage small-cell lung cancer: results from a single-center retrospective study. J Cancer Res Clin Oncol 2019; 145: 235-240. https://doi. org/10.1007/s00432-018-2764-8

[76] JIN M, CAI J, WANG X, ZHANG T, ZHAO Y. Successful maintenance therapy with apatinib inplatinum-resistant advanced ovarian cancer and literature review. Cancer Biol Ther 2018; 19: 1088-1092. https://doi.org/10.1080/153840 47.2018.1491500 